\title{
Building blocks for a cognitive science-led epistemology of arithmetic
}

\author{
Stefan Buijsman ${ }^{1,2}$ (D)
}

Accepted: 29 August 2021/Published online: 8 September 2021

(C) The Author(s) 2021

\begin{abstract}
In recent years philosophers have used results from cognitive science to formulate epistemologies of arithmetic (e.g. Giaquinto in J Philos 98(1):5-18, 2001). Such epistemologies have, however, been criticised, e.g. by Azzouni (Talking about nothing: numbers, hallucinations and fictions, Oxford University Press, 2010), for interpreting the capacities found by cognitive science in an overly numerical way. I offer an alternative framework for the way these psychological processes can be combined, forming the basis for an epistemology for arithmetic. The resulting framework avoids assigning numerical content to the Approximate Number System and Object Tracking System, two systems that have so far been the basis of epistemologies of arithmetic informed by cognitive science. The resulting account is, however, only a framework for an epistemology: in the final part of the paper I argue that it is compatible with both platonist and nominalist views of numbers by fitting it into an epistemology for ante rem structuralism and one for fictionalism. Unsurprisingly, cognitive science does not settle the debate between these positions in the philosophy of mathematics, but I it can be used to refine existing epistemologies and restrict our focus to the capacities that cognitive science has found to underly our mathematical knowledge.
\end{abstract}

Keywords Naturalistic epistemology $\cdot$ Philosophy of arithmetic $\cdot$ Approximate number system · Number acquisition · Epistemology of arithmetic

Stefan Buijsman

stefan.buijsman@gmail.com

1 Institutet för Framtidsstudier, Holländargatan 13, 10131 Stockholm, Sweden

2 Delft University of Technology, Jaffalaan 5, 2628 BX Delft, The Netherlands 


\section{Introduction}

How do we acquire mathematical knowledge? That question has kept philosophers occupied at least since Plato, and nowadays does so in its modern reformulation by Benacerraf (1973). The problem, of course, is that mathematical objects are supposed to be abstract and causally inert, which leaves it unclear how we can learn anything about them. Especially if one wants to stick to a naturalist epistemologyone on which we acquire knowledge only with faculties countenanced by science. In other words, without relying on unexplained abilities, for which e.g. the mathematical intuition proposed by Gödel (1964) is often criticized.

Over the last two decades a number of philosophers have taken this to mean that we should build our epistemology of mathematics on the findings from cognitive science. In that area, findings such as the ability to discriminate stimuli based on what is often described as their number with the Approximate Number System (ANS, cf. Dehaene, 1997; Feigenson et al., 2004) are now well-known in the philosophical literature. In fact, epistemologies of arithmetic partially based on the ANS can be found in a number of papers (Giaquinto, 2001; Jones, 2018; Yi, 2018), using the idea that numbers are learnt through a mapping with ANS-values (Dehaene, 2009). Such epistemologies suffer from a number of problems, however.

First, other philosophers have argued that the ANS cannot yield knowledge of numbers because its discriminatory ability is not precise enough: the ANS cannot distinguish between 21 and 22, or between 50 and 53. Rather, it is approximate in the sense that it can only distinguish between two stimuli if the ratio between the number of items in each is high enough (e.g. one collection has twice as many items as the other). This has been a reason for philosophers and leading cognitive scientists to argue that the ANS is insufficient for numerical knowledge (Beck, 2015; Burge, 2010; Carey, 2009; Margolis and Laurence, 2005; Núñez, 2017). While this has recently been challenged by Halberda (2016), the proponents of these epistemologies usually do not give a detailed response to these arguments.

Second, and related to the first point, Azzouni has raised what he calls the 'epistemic role objection': the problem that the capacities appealed to do not clearly have the role to respond to numerical properties. He states it as follows:

[E]xcept by the expedient of identifying the numbers with the concepts and/or notation underlying our mastery of computation and perceptual numerical recognition, such numbers visibly play no role in the successful execution of these needed abilities, regardless of what properties they turn out to have. (Azzouni, 2010, p. 30)

One can be described as recognizing that there are three objects there. One can even be described as recognizing this immediately. One does so on the basis of the objects themselves; no immediate grasping of numerical properties is to explain this. Instead, what's needed to explain this immediate grasping of a fact are subpersonal explanations. (Azzouni, 2010, p. 33)

Third, even if one can get around the philosophical argument that the imprecision in the ANS means that it cannot represent numbers one has to deal with competing 
explanations from cognitive science. A number of scientists have defended a, so far empirically well-supported, alternative account of the ANS on which it represents quantities and not numbers (Gebuis et al., 2016; Zimmerman, 2018). For a successful epistemology of arithmetic along these lines such alternative explanations of the ANS would have to be ruled out, which does not seem possible on the basis of the current empirical data (Leibovich et al., 2017).

Finally, regardless of the exact interpretation of the ANS, there is empirical evidence that suggests that the ANS plays a less important role than these epistemologies claim. Carey et al. (2017) presents evidence that children do not acquire small number concepts on the basis of the ANS. Lyons et al. (2012) found that adults have trouble comparing symbolic numbers to arrays of dots for large numbers, probably because large numbers are not associated strongly with ANS representations. An epistemology based primarily on the ANS will have to explain these experiments that suggest that, in fact, the ANS has relatively little to do with our capacities with exact numbers.

One exception to these ANS-based accounts is the epistemology put forward by Burge $(2007,2010)$. He relies, rather, on our capacity to exactly determine the number of items in very small collections:

Obviously, complex numeral names are formed from simpler ones. I think that the simpler ones are associated with a capacity for immediate, non-inferential, non-computational counting. We have a capacity to count small groups ... at a glance. We are able to apply the number in counting immediately - noninferentially through perception (Burge, 2007, p. 71)

Understanding what larger numbers are derives from this immediate hold on the applicability of the smaller ones. The concept $\underline{547}$ is formed in simple recursive fashion from the simplest canonical natural number concepts. (Burge, 2007, p. 72)

The main problem here is that the argument by Azzouni (2010) also applies to Burge's account (unsurprisingly, since Azzouni there discusses Burge's account). The psychological processes Burge relies on for our grasp of small numbers- the Object Tracking System (OTS, cf. Dehaene, 1997; Feigenson et al., 2004), a system that allows us to follow up to three or four items-also has no clear numerical content. Rather, it keeps track of several objects at once, noting their properties and locations, which allows children to register surprise when presented with sums such as 'two puppets minus one puppet = two puppets'. Not due to the mathematical inaccuracy, but because a puppet has appeared that wasn't being tracked. So, with the OTS Burge appeals to a system that has no (explicit) numerical content of its own. More than just the OTS is needed.

In short, while there have been a number of attempts to formulate an epistemology of arithmetic based on results from cognitive science, they run into trouble because they rely exclusively on the OTS and ANS. I will formulate an alternative in the rest of this paper that tries to avoid this shortcoming, relying on earlier work of mine on the acquisition of number concepts (Buijsman, 2019, 2020). Yet I will also maintain an approach similar to that of Burge (2007), dividing the 
epistemology into a part for small numbers (roughly those represented by singledigit Arabic numerals, though the OTS is more limited) and larger numbers. This is also in line with work on the relevance of the structure of numerals for any grasp of these larger numbers (Overmann, 2016; Schlimm, 2018). Furthermore, the goal of this epistemology should be clear from the outset. I do not intend to give an epistemology for a particular metaphysics. In line with the idea that the epistemology should be led by results from cognitive science I want to limit myself here to what I think those results can tell us. Rather than offering, say, a platonist epistemology, I want to set out a basis on which others can build more specific epistemologies. This might not be the only basis on which this is possible. For one, I won't be providing detailed cognitive mechanisms (partly because these are hotly debated in cognitive science, e.g. the disagreement on the mechanisms behind the ANS between Gebuis et al. (2016) and Dehaene (1997), partly because I aim at a philosophical epistemology where the focus is on what capacities people have, and less so on the cognitive mechanisms enabling them). So, there might be different accounts of the underlying cognitive mechanisms consistent with my account, and perhaps there are also viable alternatives (there is, for example, relatively little data on how larger cardinal numbers are acquired, though research is picking up in this area). Since the accounts available in the philosophical literature have all been roundly criticised, however, even having a viable option available (though it might not be the only viable option) is a step forwards.

Therefore, I first lay out a framework for the acquisition of small numbers in Sect. 2. Then, I offer an account of our grasp of larger numbers, based on that of smaller numbers, in Sect. 3. Finally, in Sect. 4, I suggest how this might lead to a full-fledged epistemology of arithmetic by linking it to two opposing metaphysical positions: ante rem structuralism and fictionalism. I hope that the end result is that we have a better idea what an epistemology of arithmetic based on results from cognitive science looks like and that it shows that such an epistemology can overcome the worries about lack of numerical content in the OTS and ANS that have plagued earlier attempts.

\section{Small numbers}

\subsection{One}

The ANS and OTS are present, as far as we can tell, from birth (Feigenson et al., 2004). I want to start a little later, with a capacity children only develop when they are roughly two years old. Before then they can distinguish between collections with one, two and three items using the OTS (because they can track the individual items in the collections). However, they cannot distinguish between collections with one and four items-in those cases their choices between the collections are at chance level (Feigenson and Carey, 2003). This changes around the two-year mark (on average, at 22 months). Then, thanks to a process that we do not yet understand, children learn to distinguish between collections with one item and all other collections with more than one item (Li et al., 2009; Sarnecka and Lee, 2009). 
However, they still exhibit at chance performance for comparisons between collections with two and four items. Because of that, this new ability is separate from the OTS.

This new ability also seems to be linked to language in interesting ways. Children who grow up hearing languages with a grammatically marked singular/plural distinction acquire this new ability faster (Barner et al., 2007; Barner and Bachrach, 2010). Children with a larger general vocabulary also need less time before they distinguish between collections with one item and those with more than one item (Negen and Sarnecka, 2012). Carey (2009) therefore suggests that children learn to distinguish collections with one item from those with more items based partially on natural language quantifiers (since if those are explicitly present children learn to make the distinction faster).

In any case, the ability to distinguish between collections with one item and those with more items does not provide us with numerical content. That is also the point made by Azzouni, when he argues that the OTS is best described as recognizing not that there are three items, but that there is one item, another one, and another, but no more than that. That idea, if one tries to formalize it, seems best captured using quantifiers (rather than numbers). So, what children learn in this stage, when they learn to distinguish collections with one item from those with more, can formally be described as them learning to recognize when $\exists ! x . F x$ is true-i.e. that 'there is an $\mathrm{F}$ and there are no other Fs'. No direct connection to numbers then, but it can nevertheless serve as basis for an epistemology of arithmetic. This is because one can fix the application conditions of ONE in terms of this quantifier, using Frege's definitions for the application conditions of numbers. He posited:

$$
\text { (DZ) } \quad 0=N x \cdot(x \neq x)
$$

However, I focus on the number one since children don't learn zero until much later:

$$
\text { (DO) } \quad \exists ! x . F x \leftrightarrow 1=N x . F x
$$

In this case there is no non-arbitrary choice of an $\mathrm{F}$ with a single instance, which is why one needs the quantifier. Importantly, though, these are the same application conditions one would get when using the standard Fregean definition of the successor function to move from zero to one. Frege formulated this instead as a predecessor relation, which means that the steps would be as follows:

$$
\begin{aligned}
& m P n \leftrightarrow F \exists y[m=N x . F x \wedge \neg F y \wedge n=N x .(F x \vee x=y)] \\
& 0 P 1 \leftrightarrow \exists y[0=N x .(x \neq x) \wedge \neg(y \neq y) \wedge 1=N x .((x \neq x) \vee x=y)]
\end{aligned}
$$

The latter is essentially my earlier version since $\neg(y \neq y)$ is guaranteed and $N x .((x \neq x) \vee x=y)$ is in effect $N x .(x=y)$ for a single object $y$.

Where does this leave us? Frege arithmetic, as established by Heck $(2000,2014)$ who showed that a reformulated version of the Dedekind-Peano axioms can be proved in Frege arithmetic (of which DP and DZ are two of the four basis, along with Hume's principle and the definition that something is a natural number if it's equal to zero or obtainable from zero using the predecessor relation). DO, as a definition which leads to consistency with the Dedekind-Peano axioms, suggests a 
way in which we can acquire some knowledge of numbers. We can apply DO correctly because of our developed ability to distinguish between singular and plural sets. The numerical content isn't present in that ability, but by abstraction via DO we can arrive at the number one nevertheless. One may worry that this is, however, still too ambitious: without Hume's principle in the background we can't be sure that the identity conditions of ONE are also correct. In order to be sure that our knowledge is of numbers, and not of a reformulation of a quantifier, HP should hold, where HP is the following principle, with $\approx$ a suitable formalization of 'is in one-toone correspondence to':

$$
N x . F x=N x . G x \leftrightarrow F \approx G
$$

Izard et al. (2014) found that once children can correctly apply 'one' they can also correctly make inferences from 'these collections have the same number of items' and 'this collection has one item' to 'this other collection has one item'. However, they cannot do so before they have learnt to correctly apply 'one' (and similarly for larger numbers, one-to-one correspondence tasks are performed successfully only after children learn to apply the number word correctly), which makes it implausible that children learn numbers on the basis of HP as a neo-logicist might suggest. The important point is that, not long after learning the application conditions, children are able to recognize the obtaining and non-obtaining of one-to-one correspondences. They recognize whether there is exactly one item in the first collection for every item in the second collection and can move from there to the claim that the number of items is the same (Izard et al., 2014; Sarnecka and Gelman, 2004; Sarnecka and Wright, 2013). In other words, children use number words in a way that is consistent with HP. Questions about numerical identity can be settled, in an appropriate way, by relying on that ability to recognize the obtaining and nonobtaining of one-to-one correspondence. This also guarantees that their concepts are consistent with Dedekind-Peano arithmetic, as the proofs by Heck $(2000$, , 2014) go through (see also Buijsman, 2019).

Note that I am not proposing a neo-logicist epistemology in line with e.g. Hale and Wright (2002). Number concepts are not acquired through implicit definition on HP, but rather through DO and successive applications of DP. HP is needed to ensure the infinity of the natural numbers, but I have an alternative explanation based on the syntax of our numeral system for the consistency of number concepts with that axiom (i.e. how children learn that there are infinitely many numbers; Buijsman, 2020). Therefore, I am not suggesting that our knowledge of numbers stems solely from HP combined with knowledge of one-to-one correspondences, thus avoiding difficulties with reference on the basis of an abstraction principle.

Instead, I hold that knowledge that two collections have the same number of items is based on the ability to recognize the obtaining of one-to-one correspondences, whereas knowledge that there is one F derives from the ability to distinguish between singular and plural sets. More numbers are needed for any kind of arithmetic, so I turn next to the remaining small numbers-roughly those denoted by single-digit numerals. I say roughly, because it is not quite clear where the border is (if there is a clear-cut border). This will depend on when when we start to rely on 
the structure of the numeral system (see Sect. 3) and so on when the quantifierbased grasp of numbers I outline in this section becomes too cumbersome.

\subsection{Two, three, ...}

In my opinion the same abilities that underlie knowledge about the number one also support our knowledge of the other small numbers. By repeated use of the ability to distinguish singular and plural sets it is possible to evaluate not just $\exists$ ! $x$. Fx but also higher cardinal quantifiers, denoted for simplicity with a number: $\exists_{2} x . F x, \exists_{3} x . F x$, etc. Of course, these are nothing more than abbreviations for lists of quantifiers. They have, for that reason, no explicit numerical content. In order to arrive at numbers one has to, once again, appeal to the Fregean definitions. In particular, to DP (stated earlier), the definition of the predecessor relation/successor function.

The idea is as follows: while children are acquiring number concepts, they do so in strict order (Wynn, 1992). So, after they have acquired one they acquire two by figuring out that a collection has two items precisely when it is made up of one item and another single item. The same then happens for THREE: that applies to all collections with two items to which precisely one item is added. At least, so I have argued in Buijsman (2019), as the alternative suggestion that it is just the OTSwith children forming long-term memory models that they compare to the collection to be counted-by Carey (2009) cannot explain why these numbers are learnt in order.

An epistemology for small numbers can build on that idea. While acquiring number concepts, children learn to evaluate the relevant quantifiers (or rather, they learn to distinguish between ever more collections based on the items in them, which is formalized in the most minimal way using quantifiers, again in line with the arguments mentioned in Sect. 1). One reason for thinking that they take a detour via quantifiers, at least for small numbers, is that afterwards we are able to decide on the number of items in a collection on the basis of the OTS (Cheung and Le Corre, forthcoming). The OTS, as I mentioned earlier, has no numerical content of its own. So, in the absence of a counting procedure (as in the study by Cheung and Le Corre, forthcoming) it seems likelier that the OTS is extended while acquiring number concepts, to allow the evaluation of (exact) cardinal quantifiers. In other words, during the acquisition process we also learn to distinguish collections with two items from all other collections and can then do so automatically, as with singular v.s. plural sets.

Given that we acquire this capacity to evaluate also $\exists_{2} x . F x, \exists_{3} x . F x$ and $\exists_{4} x . F x$ supported by the OTS, the epistemology for these small numbers can be quite similar. How do we know when to correctly apply one of these numbers to a collection of items? On the basis of the quantifiers we are able to evaluate. How do we judge whether two collections have the same number of items? On the basis of the ability to recognize one-to-one correspondences between collections. Yet, how do we move from here to knowledge of, say, $1+1=2$ ? The details will, of course, depend on one's preferred metaphysics. Postponing those metaphysical questions to Sect. 4 , is there something to be said here? 
Regardless of one's position, with my account one seems to arrive at pure arithmetical statements by abstraction. The Fregean definitions that give us the application and identity conditions for numbers can be the basis for such an abstraction procedure that leads to pure arithmetical statements. For, it is possible to derive suitable reformulations of the Dedekind-Peano axioms in Frege arithmetic (Heck, 1997,, 2000,, 2014; Linnebo, 2004). The Dedekind-Peano axioms are not about applied arithmetical statements, which means that it is possible to move from the application and identity conditions for applied arithmetical statements to truthconditions of pure arithmetical statements. Those pure arithmetical statements do not have to be interpreted as abbreviations for statements about quantifiers.

Note though that what seem like arithmetical sentences might actually, in a large number of cases, be sentences about quantifiers. A number of accounts in the philosophical literature hold that the a swathe of arithmetical sentences in natural language such as 'two and two is four' are best interpreted along adjectival lines, i.e. as something like 'two things and two other things are (together) four things' (Barlew, 2017; Felka, 2014; Hofweber, 2005; Jackson, 2013; Moltmann, 2013, 2017; Roberts and Shapiro, 2017). While controversial, and certainly not true for all arithmetical sentences (e.g. 'seventeen is odd' very likely is about numbers), it could imply that a lot of the sentences used by children have terms functioning as quantificational determiners rather than as singular terms referring to numbers. This would actually fit well with the current suggestion: we arrive at knowledge of these sentences about quantifiers/referents of quantificational determiners ${ }^{1}$ on the basis of our developed ability to evaluate such quantifiers. Of course, this is not arithmetical knowledge, as it does not concern numbers. For numerical knowledge one will have to, on my account, follow an abstraction procedure. Still, if the linguists are right then our facility with such natural language statements can be explained on the same basis as the one I am suggesting for our knowledge of numbers. Proper access to numbers will have to come from an abstraction procedure, but facility with a large number of natural language statements can be explained through cardinal quantifiers alone.

This leaves one last issue to do with 'small' numbers: the enhanced OTS only extends up to about four, which is why I ended at $\exists_{4} x . F x$ earlier. So, if what I term larger numbers start at the earliest from 10, there is still a gap that needs to be filled. While no system is available to do so at a glance, I don't think one is required. Counting, whether by shifting visual attention or actually using your fingers, is the obvious alternative. Unsurprisingly children at first evaluate pure arithmetical statements using (finger) counting (see e.g. Butterworth, 2005; Dowker, 2008; Jordan, 2008; Siegler and Robinson, 1982). Such finger counting can support the evaluation of quantifiers: children might, for example, learn that the quantifier $\exists_{5} x$.Fx applies precisely when one has added single items often enough to reach the number word 'five'.

\footnotetext{
1 If one prefers a different formalization than first-order quantifiers then that shouldn't matter for my view. I see no reason why our ability to distinguish singular from plural sets cannot be described in terms of e.g. plural properties instead, which is how the referents of quantificational determiners are sometimes formalized.
} 
Merely going through the count sequence, set up in one-to-one correspondence with the collection one is counting is not enough: children can do this before they have acquired any number concepts, treating the count sequence similar to other word sequences such as 'eeny, meeny, miny, moe' (Carey, 2009; Sarnecka and Lee, 2009; Wynn, 1992). By combining the counting procedure with the ability to evaluate $\exists ! x . F x$ it can get coupled to our number concepts and, via the Fregean DP, it can give us knowledge of numbers beyond the reach of the OTS. We can correctly apply the number five by counting from four, adding exactly one item, to reach five. The counting procedure extends our ability to evaluate cardinal quantifiers, which via the Fregean definitions leads to knowledge of numbers larger than four. Counting is thus the last piece of my view of our knowledge of 'small' numbers, with the explanation of application and identity conditions of the number concept, and our knowledge of pure arithmetical statements proceeding as it did for the other parts of my account for small numbers.

\section{Larger numbers}

We don't typically count collections with very many items ourselves. Nor does it seem likely that we evaluate arithmetical sums with large numbers on the basis of counting, whereas this is quite plausible for small sums (before we just retrieve the results from memory). For example, when required to solve $13089+4386$ we don't start counting from 13089 until we reach the correct answer. Instead, we perform the addition on a digit-by-digit basis. That is the basis for my account regarding our knowledge of larger numbers. As mentioned in the introduction, Burge (2010) suggests something similar, though with less details from cognitive science. Schlimm (2018), on the other hand, has argued for the role of the structure of the numeral system using results from cognitive science but without connecting it to an epistemology. I combine those two strands here.

The main reason for doing so is that an array of studies in cognitive science have shown that the human brain processes multi-digit numerals in a decomposed fashion: when you read a numeral such as 475 your brain automatically separates it into 4, 7 and 5 (García-Orza and Damas, 2011; Moeller et al., 2011; Nuerk et al., 2015). Any operations are, researchers now think, performed with the single digits, before recombining them into the final result (Ashcraft and Stazyk, 1981; Domahs et al., 2006; Sandrini et al., 2003; Verguts and Fias, 2005). Good reason, then, to think that our grasp of these numbers is based on a more basic hold on small numbers, combined with a knowledge of the structure of the numeral system. For example, that we acquire knowledge of the outcome of $13089+4386$ on the basis of our knowledge of the sums for individual digits $(9+6,8+8+1$, etc. $)$ together with our knowledge of how to combine the outcomes of those smaller sums to arrive at the final answer.

This knowledge of the structure of the numeral system needs to be learned, and that can take quite a while (Fuson, 1990; Fuson and Briars, 1990). Children in primary school who are learning to add multi-digit numbers often display errors 
related to the structure of the numeral system. Lengnink and Schlimm (2010) discuss one example of a child performing the following addition:

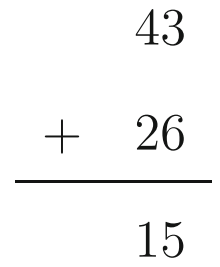

In this case the confusion is that the fact that ' 4 ' and ' 2 ' occur in the decade position is ignored: the child performs the addition $4+3+2+6=15$. Before they realise mistakes of that kind children often need to learn to count up to 100 first. Only then do they acquire an understanding of the (syntactic, place-value) structure of the numeral system (Fuson and Hall, 1983; Siegler and Robinson, 1982; Rule et al., 2015; Guerrero et al., 2020). That means that any suggestion that larger numbers are grasped in terms of the structure of the numeral system needs to acknowledge that there is an intermediate stage, at least for numbers below 100.

I don't think that such an intermediate stage is particularly problematic. The counting procedure that I outlined for 'small' numbers works just as well for larger numbers, but is much less efficient than the eventual use of the structure of the numeral system. Besides, performance on tasks involving larger numbers tends to be imperfect before children can count to around 100. Davidson et al. (2012) and Cheung et al. (2017) found that children often cannot answer questions of the type 'there are $n$ items in this box, how many are there if I add one?' for larger numbers, before children can count to 100 , even though such numbers are within their count list. The intermediate stage can thus be accounted for in terms of counting, where the sub-optimal performance is in line with the practical limitations of counting larger collections of items. We simply do not have as clear an idea of a collection with 76 items as of a collection with 7 items.

But then how does it work, in detail, once we do know the structure of the numeral system? Our knowledge of smaller numbers, and the results of arithmetical operations on those smaller numbers, has been accounted for in the previous section. However, there is a question left on the recombination of these individual results into the final answer. This requires multiplication with powers of 10, yet those numbers (e.g. 100,000) are themselves often larger than the small numbers with which the reduction is supposed to end.

How this problem is best resolved depends, of course, on how the brain implements this knowledge of the structure of the numeral system. As far as I am aware, we don't know much about the actual processes yet-they are decomposed in the sense that digits are treated separately, but we don't know how they are recombined; how the brain internalises their place-value. One option, though, is that there is indeed a complete reduction to small numbers. We use our grasp of 10 through counting, along with the idea that every next digit has ten times the value. A hundred can be processed as $10 \times 10$, a thousand as $10 \times 10 \times 10$, and so on. For very large numbers, where the number of trailing zeroes is often used to indicate 
size, that seems the right conclusion. Whether it is also correct for a hundred, which we seem to grasp more directly, is something open to debate (it could just be the result of very frequent encounters with numbers that size). The mere fact that we don't notice the calculation is not enough-after all, we also don't notice the decomposition of multi-digit numerals even though there is ample evidence that the brain processes numerals in that way. More evidence is needed, but it is at least possible to deal with the structure of the numeral system in terms of iterated multiplication with ten.

For larger numbers, then, we can use the structure of the numeral system to acquire knowledge - thanks to our more primitive grasp of small numbers. Pure arithmetical statements can be verified by performing calculations with the individual digits. Those calculations with small numbers lead to knowledge through counting procedures and quantifier evaluations, in other words through the detour of cardinal quantifiers and the Fregean definitions of number. How that structure is grasped precisely has been left open. I have suggested that iterated multiplication with 10 is a way out, though this may be too indirect for a hundred and a thousand. It also necessitates further reductions once there are very many zeroes: $10^{56}$ is a number that can be grasped only after we have reduced the 56 to its component digits, to know how many times we need to multiply with 10 . We will have to await more details on how the brain actually decomposes and recomposes multi-digit numerals before we can be confident of having the right answer. Yet a reduction to small numbers seems an important part of an epistemology of arithmetic that fits how we actually acquire arithmetical knowledge. For that is how the brain deals with large numbers: by decomposition (Nuerk et al., 2015).

As a final note to this section, I should point out that the suggested account here is not restricted to those who know the Hindu-Arabic numeral system. As a reviewer rightly pointed out, historically there have been other numeral systems, and currently some cultures still use different numeral systems. All of these numeral systems, crucially, have a recursive structure that uses a small base to describe larger numbers (and so the same idea of acquiring knowledge about large numbers through knowledge of small numbers applies). To give a few examples: the Babylonian numeral system is often thought of as having base 60 , but actually has a repeating 10-6 cycle; there are different signs until 10 and then every decade (20, $30,40,50$ ) gets a new sign until you reach 60 , which is the sign for 1 (Høyrup, 2001). The Roman numeral system changes symbols in a 5-2 cycle: first at 5 (V), then at $10(\mathrm{X})$, then $50(\mathrm{~L})$, then $100(\mathrm{C})$, etc. The Oceanic language Mangarevan contains two numeral systems: a decimal system and a system that mixes decimal and binary patterns (Bender and Beller, 2017). A common feature of all these systems is a recursive structure with a base no higher than that for Hindu-Arabic numerals. So my account should work for the whole range of numeral systems that has been, and is, in use. It is thus a good basis for a full epistemology of arithmetic, to which I turn next. 


\section{Building a full-fledged epistemology}

I have discussed the general structure of an epistemology of arithmetic in the previous two sections. The processes through which we acquire mathematical knowledge were mapped, and I suggested how these processes might arrive at numerical content-the main issue with previous attempts to formulate an epistemology based on results from cognitive science. However, that alone does not solve the philosophical issues with our arithmetical knowledge. We also need an account of what numbers are, i.e. what exactly this numerical content amounts to, and how the identified psychological processes can yield knowledge of precisely that kind of numerical content. Since my focus here is on what guidance we can get from cognitive science for the philosophical project I have tried not to commit myself to any particular view of the nature of numbers. I doubt that cognitive science can decide between all the competing philosophical accounts. Therefore, I want to suggest that the current work can be used to refine existing epistemologies. In order to substantiate that suggestion I consider two accounts in this section, ante rem structuralism and fictionalism and argue that both could make use of the work from the previous two sections.

Ante rem structuralism is the position that mathematical objects are completely characterized by their structural properties, i.e. that they are nothing more than positions in certain structures, which exist (this is the 'ante rem' part) independently from any instances that exemplify these structures. In the case of the numbers this means that: "The essence of a natural number is its relations to other natural numbers ...The number 2, for example, is no more and no less that the second position in the natural number structure; 6 is the sixth position." (Shapiro, 1997, p. 72, original italics)

In order to arrive at knowledge of these numbers Shapiro suggests that one starts with very simple structures known as finite cardinal structures:

For each natural number $n$, there is a structure exemplified by all systems that consist of exactly $n$ objects. For example, the 4 pattern is the structure common to all collections of four objects. The 4 pattern is exemplified by the starting infielders on a baseball team (not counting the battery), the corners of my desk, and two pairs of shoes. We define the 2 pattern, 3 pattern, and so on, similarly. Let us call these "cardinal structures," or "finite cardinal structures." The finite cardinal structures have no relations and so are as simple as structures get. (Shapiro, 1997, p. 115, original italics)

We learn about these finite cardinal structures through ostensive definition according to Shapiro, at least in the case of small numbers:

In part, our child starts to learn about cardinal structures by ostensive definition. The parent points to a group of four objects, says "four," then points to a different group of four objects and repeats the exercise. Eventually, the child learns to recognize the pattern itself. (Shapiro, 1997, p. 115) 
This is where my account from Sect. 2 fits in. Shapiro builds his epistemology on the idea that children can recognize the pattern behind different instances where a parent points to a collection of four items. My discussion from Sect. 2 fills in the details by offering an explanation how children manage to recognize that pattern. They do so through the mechanisms for evaluating quantifiers that cognitive scientists are studying. Shapiro then has to do the additional work of explaining why this pattern recognition helps us to arrive at knowledge of an abstract finite cardinal structure. In that sense the current work doesn't resolve the demand on platonists to provide an epistemology: we still need an argument why this way to recognize a pattern between cases leads to knowledge of an abstract structure rather than to knowledge of something acceptable to nominalists. Yet my work refines this first part of Shapiro's epistemology because it clarifies the nature of the pattern recognition he appeals to.

The same holds for Shapiro's suggestions regarding larger numbers. He offers two options:

Returning to our learning child, perhaps she reflects on the sequence of numerals, eventually noting that the sequence goes beyond the collections she has actually counted. She then sees that any finite collection can be counted and thus has a cardinality. (Shapiro, 1997, p. 117)

A related possibility is that humans have a faculty that resembles pattern recognition but goes beyond simple abstraction. The small finite structures, once abstracted, are seen to display a pattern themselves. For example, the finite cardinal structures come in a natural order: the 1 pattern, followed by the 2 pattern, followed by the 3 pattern, and so on. We then project this pattern of patterns beyond the structures obtained by simple abstraction. (Shapiro, 1997, p. 118)

Again, it should be clear how my Sect. 3 can be used to expand on these two suggestions. I have argued for a combination of the two: children and adults use a pattern as in the second suggestion, but the pattern is that of the numerals (as per the first suggestion). It is the pattern underlying the numeral system that one should focus on, and not the pattern of the numbers under the successor function.

In short, my account from Sects. 2 and 3 can be plugged into the epistemology provided by Shapiro (1997) in a fairly straightforward manner. It requires that one argues that the capacities I have appealed to lead to knowledge of patterns and that those patterns are best interpreted as ante rem structures. That there are patternsthat shared between collections with a small number of items and that underlying the numeral system-is clear. The difficult part is to argue that those should be interpreted as ante rem structures. Of course, that is a wide-ranging philosophical debate, which also includes arguments over what kind of ante rem structures are acceptable (see Button, 2006; Hellman, 2005; Keränen, 2001; Macbride, 2006 for one view and Shapiro, 2006, 2008, 2012; Leitgeb and Ladyman, 2008 for another). The point is that it is possible to work out an epistemology for ante rem structuralism in more detail using the current work. It might even help for a more 
detailed debate as to whether or not these abilities can be interpreted such that they lead to knowledge of ante rem structures.

Should one decide that our capacities do not lead to knowledge of ante rem structures then the current work fits just as well with nominalist epistemologies. As an example, one can look at fictionalism: "the fictionalist considers that the methods of pure mathematics ...provide us with knowledge of logical consequence-even though she rejects the claim that these methods give us any genuine mathematical knowledge" (Leng, 2007, p. 87). There are different ways of spelling this out in detail; Leng (2007) talks mostly about axioms whereas Bueno (2009) relies more heavily on descriptions of objects in general (whether they are axioms or not):

Knowledge of mathematical entities, just as knowledge of fictional entities in general, is the result of producing suitable descriptions of the objects in question and drawing consequences from the assumptions that are made. (Bueno, 2009, p. 73)

On this approach to mathematical "knowledge", the existence of mathematical objects, relations, or structures plays no role. What matters is what can be derived from the relevant principles, assuming a given logic. (Bueno, 2011, p. 366)

Here is one suggestion for combining this kind of epistemology with my account. While children (and most adults) may not have axioms or particular descriptions in mind, they do have natural number concepts. In fact, they have natural number concepts which, as I have argued in Buijsman (2019), are consistent with the second-order Dedekind-Peano axioms. The mathematical knowledge they acquire through the processes I have outlined earlier can then be seen as ways to find out consequences of those concepts.

in particular, the ability to evaluate (small) cardinal quantifiers allows us to find out that a number concept applies to a particular collection of items. Similarly, the ability to recognize that a one-to-one correspondence obtains between two collections allows us to find out that the same number concept applies to those two collections. In terms closer to those used by Bueno: the number of items is the same, given the way numbers are described. Pure arithmetical statements are not much different; either we learn that $1+1=2$ is a consequence of our number concepts through an abstraction procedure, or we rely on our ability to work with cardinal quantifiers to settle the natural language version 'one and one is two'. Finally, for larger numbers we find out consequences of our number concepts by relying on the structure of the numeral system.

While this way of fitting my account into fictionalism may not quite fit the explicit statements of some fictionalists, such as when Leng says that fictionalists "need to account for our knowledge of the consistency of those theories, and for our knowledge of what follows logically from their axioms" (Leng, 2007, p. 84), it is in line with the spirit of those accounts. No fictionalist is likely to think that children actually arrive at arithmetical knowledge through a logical derivation from the Dedekind-Peano axioms. My suggestion, that they arrive at arithmetical knowledge by finding out consequences of number concepts that are consistent with the 
Dedekind-Peano axioms, seems a plausible way of avoiding such an extreme view while staying close to the claims of fictionalists. As a result, the framework for an epistemology of arithmetic that I have presented in Sects. 2 and 3 can also be built into a nominalist epistemology.

\section{Conclusion}

I have explored what results from cognitive science might add to an epistemology of arithmetic. Previous attempt at such work have been criticized for an overly ambitious, i.e. overly numerical, interpretation of our cognitive abilities. In particular, they assigned numerical content to the ANS and/or the OTS, and appealed to these systems to account for our arithmetical knowledge. I have tried to avoid these issues by sticking to an interpretation of the early systems in purely logical (quantifier) terms and by not appealing to the ANS in my own framework for an epistemology.

Instead, I appealed to our ability to distinguish between singular and plural sets, interpreted by e.g. Carey (2009) as the ability to evaluate a quantifier, as the basis for an epistemology. Thanks to the Fregean definitions this ability offers a way to learn about the application conditions of number concepts. Combined with the OTS and the counting procedure this leads to a way in which one can learn about small numbers. The structure of the numeral system, by way of the decomposed way in which our brain processes multi-digit numerals, shows that we can learn about larger numbers on the basis of this knowledge of small numbers.

Yet all these findings provide no more than a framework for an epistemology of arithmetic. As I have also argued, this framework can fit into different philosophical accounts of numbers. Both ante rem structuralism and fictionalism are compatible with the framework I have outlined; they merely differ in how they interpret the knowledge that results from using the capacities I described in Sects. 2 and 3. Cognitive science, as one would expect, does not settle these philosophical debates. It does, however, give us a more refined picture of the processes by which we acquire mathematical knowledge and, as such, the processes out of which one should build a complete epistemology of arithmetic.

Acknowledgements Funding was provided by Royal Swedish Academy of Sciences (Grant No. 2018-01163).

Open Access This article is licensed under a Creative Commons Attribution 4.0 International License, which permits use, sharing, adaptation, distribution and reproduction in any medium or format, as long as you give appropriate credit to the original author(s) and the source, provide a link to the Creative Commons licence, and indicate if changes were made. The images or other third party material in this article are included in the article's Creative Commons licence, unless indicated otherwise in a credit line to the material. If material is not included in the article's Creative Commons licence and your intended use is not permitted by statutory regulation or exceeds the permitted use, you will need to obtain permission directly from the copyright holder. To view a copy of this licence, visit http:// creativecommons.org/licenses/by/4.0/. 


\section{References}

Ashcraft, M., \& Stazyk, E. (1981). Mental addition: A test of three verification models. Memory \& Cognition, 9, 185-96.

Azzouni, J. (2010). Talking about nothing: Numbers, hallucinations and fictions. Oxford University Press.

Barlew, J. (2017). Focus on numbers. Linguistics and Philosophy, 40, 401-426.

Barner, D., \& Bachrach, A. (2010). Inference and exact numerical representation in early language development. Cognitive Psychology, 60, 40-62.

Barner, D., Thalwitz, D., Wood, J., Wang, S., \& Carey, S. (2007). On the relation between the acquisition of singular-plural morpho-syntax and the conceptual distinction between one and more than one. Developmental Science, 10(3), 365-373.

Beck, J. (2015). Analogue magnitude representations: A philosophical introduction. British Journal for the Philosophy of Science, 66(4), 829-855.

Benacerraf, P. (1973). Mathematical truth. The Journal of Philosophy, 70(19), 661-679.

Bender, A., \& Beller, S. (2017). The power of 2: How an apparently irregular numeration system facilitates mental arithmetic. Cognitive Science, 41, 158-187.

Bueno, O. (2009). Mathematical fictionalism. In Bueno, O., \& Linnebo, Ø. (Eds.), New waves in the philosophy of mathematics (pp. 59-79).

Bueno, O. (2011). Logical and mathematical knowledge. In Bernecker, S., \& Pritchard, D. (Eds.), Routledge companion to epistemology (pp. 358-368).

Buijsman, S. (2019). Learning the natural numbers as a child. Noûs, 53(1), 3-22.

Buijsman, S. (2020). Two roads to the successor axiom. Synthese, 197(3), 1241-1261.

Burge, T. (2007). Foundations of mind. Oxford University Press.

Burge, T. (2010). Origins of objectivity. Oxford University Press.

Butterworth, B. (2005). The development of arithmetical abilities. Journal of Child Psychology and Psychiatry, 46(1), 3-18.

Button, T. (2006). Realistic structuralism's identity crisis: A hybrid solution. Analysis, 66(3), 216-22.

Carey, S. (2009). The origin of concepts. Oxford University Press.

Carey, S., Shusterman, A., Haward, P., \& Distefano, R. (2017). Do analog number representations underlie the meanings of young children's verbal numerals? Cognition, 168, 243-255.

Cheung, P., \& Le Corre, M. (forthcoming). Parallel individuation supports numerical comparisons in preschoolers. Journal of Numerical Cognition. Retrieved from https://psyarxiv.com/sk97d/.

Cheung, P., Rubenson, M., \& Barner, D. (2017). To infinity and beyond: Children generalize the successor function to all possible numbers years after learning to count. Cognitive Psychology, 92, 22-36.

Davidson, K., Eng, K., \& Barner, D. (2012). Does learning to count involve a semantic induction? Cognition, 123, 162-173.

Dehaene, S. (1997). The number sense: How the mind creates mathematics. Oxford University Press.

Dehaene, S. (2009). Origins of mathematical intuitions. Annals of the New York Acadamy of Natural Sciences, 1156(1), 232-259.

Domahs, F., Delazer, M., \& Nuerk, H. (2006). What makes multiplication facts difficult. Experimental Psychology, 53, 275-82.

Dowker, A. (2008). Individual differences in numerical abilities in preschoolers. Developmental Science, 11(5), 650-654.

Dummett, M. (1991). Frege: Philosophy of mathematics. Cambridge: Harvard University Press.

Feigenson, L., \& Carey, S. (2003). Tracking individuals via object-files: Evidence from infants' manual search. Developmental Science, 6(5), 568-584.

Feigenson, L., Dehaene, S., \& Spelke, E. (2004). Core systems of number. Trends in Cognitive Sciences, $8(7), 307-314$.

Felka, K. (2014). Number words and reference to numbers. Philosophical Studies, 168, 261-282.

Fuson, K., \& Hall, J. (1983). The acquisition of early number word meanings: A conceptual analysis and review. In Ginsburg (Ed.), The development of children's mathematical thinking (pp. 49-107).

Fuson, K. (1990). Issues in place-value and multidigit addition and subtraction learning and teaching. Journal for Research in Mathematics Education, 21(4), 273-280. 
Fuson, K., \& Briars, D. (1990). Using a base-ten blocks learning/teaching approach for first-and secondgrade place-value and multidigit addition and subtraction. Journal for Research in Mathematics Education, 21(3), 180-206.

García-Orza, J., \& Damas, J. (2011). Sequential processing of two-digit numbers: Evidence of decomposition from a perceptual number matching task. Journal of Psychology, 219(1), 23-29.

Gebuis, T., Kadosh, R. C., \& Gevers, W. (2016). Sensory-integration system rather than approximate number system underlies numerosity processing: A critical review. Acta Psychologica, 171, 17-35.

Giaquinto, M. (2001). Knowing numbers. The Journal of Philosophy, 98(1), 5-18.

Gödel, K. (1964). What is Cantor's continuum problem. In P. Benacerraf \& H. Putnam (Eds.), Philosophy of mathematics (pp. 470-485). Cambridge University Press.

Guerrero, D., Hwang, J., Boutin, B., Roeper, T., \& Park, J. (2020). Is thirty-two three tens and two ones? The embedded structure of cardinal numbers. Cognition, 203, 104331.

Halberda, J. (2016). Epistemic limitations and precise estimates in analog magnitude representation. In Barner, D. \& Baron, S. (Eds.), Core knowledge and conceptual change (pp. 171-190).

Hale, B., \& Wright, C. (2002). Benacerraf's dilemma revisited. European Journal of Philosophy, 10(1), 101-129.

Heck, R., Jr. (1997). Finitude and Hume's principle. Journal of Philosophical Logic, 26(6), 589-617.

Heck, R., Jr. (2000). Cardinality, counting, and equinumerosity. Notre Dame Journal of Formal Logic, 41(3), 187-209.

Heck, R., Jr. (2014). Predicative Frege arithmetic and 'everyday' mathematics. Philosophia Mathematica, 22(3), 279-307.

Hellman, G. (2005). Structuralism. In S. Shapiro (Ed.), The Oxford handbook of philosophy of mathematics and logic (pp. 536-562).

Hofweber, T. (2005). Number determiners, numbers, and arithmetic. The Philosophical Review, 114(2), $179-225$.

Høyrup, J. (2001). Early Mesopotamia: A Statal Society Shaped by and Shaping Its Mathematics. Contribution to "Les Mathematiques et l'état", Cirm-Luminy, 15 octobre-19 octobre 2001. Mimeo, Roskilde University. http://akira.ruc.dk/ jensh/Publications/2001\%7BK\%7D04_Luminy.pdf

Izard, V., Streri, A., \& Spelke, E. (2014). Toward exact number: Young children use one-to-one correspondence to measure set identity but not numerical equality. Cognitive Psychology, 72, 27-53.

Jackson, B. (2013). Defusing easy arguments for numbers. Linguistics and Philosophy, 36, 447-461.

Jones, M. (2018). Seeing numbers as affordances. In S. Bangu (Ed.), Naturalizing logico-mathematical knowledge: Approaches from philosophy, psychology and cognitive science (pp. 148-163). New York: Routledge.

Jordan, N., Kaplan, D., Ramineni, C., \& Locuniak, M. (2008). Development of number combination skill in the early school years: When do fingers help? Developmental Science, 11(5), 662-668.

Keränen, J. (2001). The identity problem for realist structuralism. Philosophia Mathematica, 9(3), 308-30.

Leibovich, T., Katzin, N., Harel, M., \& Henik, A. (2017). From 'sense of number' to 'sense of magnitude': The role of continuous magnitudes in numerical cognition. Behavioral and Brain Sciences, 40, e164.

Leitgeb, H., \& Ladyman, J. (2008). Criteria of identity and structuralist ontology. Philosophia Mathematica, 16, 388-396.

Leng, M. (2007). What's there to know? A fictionalist account of mathematical knowledge. In M. Leng, A. Paseau, \& M. Potter (Eds.), Mathematical knowledge (pp. 83-108). Oxford University Press.

Lengninik, K., \& Schlimm, D. (2010). Learning and understanding numeral systems: Semantic aspects of number representations from an educational perspective. Philosophy of Mathematics: Sociological Aspects and Mathematical Practice, 11, 235-264.

Linnebo, Ø. (2004). Predicative fragments of Frege arithmetic. The Bulletin of Symbolic Logic, 10(2), $153-174$.

Li, P., Ogura, T., Barner, D., Yang, S., \& Carey, S. (2009). Does the conceptual distinction between singular and plural sets depend on language? Developmental Psychology, 45(6), 1644-1653.

Lyons, I., Ansari, D., \& Beilock, S. (2012). Symbolic estrangement: Evidence against a strong association between numerical symbols and the quantities they represent. Journal of Experimental Psychology: General, 141(4), 635-641.

MacBride, F. (2006). What constitutes the numerical diversity of mathematical objects? Analysis, 66(289), 63-9. 
Margolis, E., \& Laurence, S., et al. (2005). Number and natural language. In P. Carruthers (Ed.), The innate mind: Structure and contents (Vol. 1, pp. 216-235). Oxford University Press.

Moeller, K., Huber, S., Nuerk, H., \& Wilmes, K. (2011). Two-digit number processing: Holistic, decomposed or hybrid? A computational modelling approach. Psychological Research, 75(4), 290-306.

Moltmann, F. (2013). Reference to numbers in natural language. Philosophical Studies, 162, $499-536$.

Moltmann, F. (2017). Number words as number names. Linguistics and Philosophy, 40, 331-345.

Negen, J., \& Sarnecka, B. (2012). Number-concept acquisition and general vocabulary development. Child Development, 83(6), 2019-2027.

Nuerk, H., Moeller, K., \& Willmes, K. (2015). Multi-digit Number Processing: Overview, conceptual clarifications, and language influences. In C. Kadosh \& A. Dowker (Eds.), The Oxford handbook of numerical cognition (pp. 106-139). OUP.

Núñez, R. (2017). Is there really an evolved capacity for number? Trends in Cognitive Sciences, 21, 409-424.

Overmann, K. (2016). The role of materiality in numerical cognition. Quaternary International, 405, 42-51.

Roberts, C., \& Shapiro, S. (2017). Ontology via semantics? Introduction to the special issue on the semantics of cardinals. Linguistics and Philosophy, 40, 321-329.

Rule, J., Dechter, E., \& Tenenbaum, J. (2015). Representing and learning a large system of number concepts with latent predicate networks. In Noelle, D., Warlaumont, Y., Matlock, J. \& Maglio (Eds.), Proceedings of the 37th annual meeting of the Cognitive Science Society (pp. 2051-2056).

Sandrini, M., Miozzo, A., Cotelli, M., \& Cappa, S. (2003). The residual calculation abilities of a patient with severe aphasia: Evidence for a selective deficit of subtraction procedures. Cortex, 39, 85-96.

Sarnecka, B., \& Gelman, S. (2004). Six does not just mean a lot: Preschoolers see number words as specific. Cognition, 92, 329-352.

Sarnecka, B., \& Lee, M. (2009). Levels of number knowledge during early childhood. Journal of Experimental Child Psychology, 103, 325-337.

Sarnecka, B., \& Wright, C. (2013). The idea of an exact number: Children's understanding of cardinality and equinumerosity. Cognitive Science, 37(8), 1493-1506.

Schlimm, D. (2018). Numbers through numerals: The constitutive role of external representations. In S. Bangu (Ed.), Naturalizing logico-mathematical knowledge: approaches from philosophy, psychology and cognitive science (pp. 195-217). New York: Routledge.

Shapiro, S. (2006). Structure and identity. In MacBride, F. (Ed.), Identity and modality (pp. 109-145).

Shapiro, S. (2012). An "i" for an i: Singular terms, uniqueness, and reference. The Review of Symbolic Logic,5(3), 380-415.

Shapiro, S. (1997). Philosophy of mathematics: Structure and ontology. New York: Oxford University Press.

Shapiro, S. (2008). Identity, indiscernibility, and ante rem structuralism: The tale of i and -i. Philosophia Mathematica, 16, 285-309.

Siegler, R., \& Robinson, M. (1982). The development of numerical understandings. In Reese \& Lipsett (Eds.), Advances in child development and behaviour (Vol. 16, pp. 242-312).

Siegler, R. (1984). Strategy choices in addition and subtraction: How do children know what to do? In C. Sophian (Ed.), Origins of cognitive skill: The eighteenth annual Carnegie symposium on cognition (pp. 229-293). New York: Lawrence Erlbaum Associates.

Verguts, T., \& Fias, W. (2005). Neighborhood effects in mental arithmetic. Psychology Science, 47, $132-140$.

Wynn, K. (1992). Addition and subtraction by human infants. Nature, 358, 749-750.

Yi, B. (2018). Numerical cognition and mathematical knowledge: The plural property view. In S. Bangu (Ed.), Naturalizing logico-mathematical knowledge: Approaches from philosophy, psychology and cognitive science (pp. 52-88). New York: Routledge.

Zimmerman, E. (2018). Small numbers are sensed directly, high numbers constructed from size and density. Cognition, 173, 1-7.

Publisher's Note Springer Nature remains neutral with regard to jurisdictional claims in published maps and institutional affiliations. 